\title{
Novel Dummy Load for 40W Fluorescent Lamps
}

\author{
Bo-Hwan Choi ${ }^{*}$, Hyun-Jae Kim ${ }^{* *}$, In-Yong Yeo ${ }^{*}$, Bong-Cheol Kim ${ }^{* * *}$, and Chun-Taek Rim ${ }^{\dagger}$ \\ ${ }^{\dagger *}$ Department of Nuclear and Quantum Engineering, KAIST, Daejeon, Korea \\ ${ }^{* *}$ Department of Electrical Engineering, KAIST, Daejeon, Korea \\ ${ }^{* * *}$ Optomind Inc., Suwon, Korea
}

\begin{abstract}
A new fluorescent dummy load to replace one of the fluorescent lamps in a dual lamp type rapid-start ballast for halving the lamp power is proposed. Using a circuit composed of a fundamental compensation circuit and a harmonic filter circuit, a new fluorescent dummy load having superior characteristics than a conventional dummy load is developed. The design principle and architecture of the proposed fluorescent dummy load is explained and verified by experiments.
\end{abstract}

Key words: Fluorescent lamp, Dummy load, Rapid-start ballast

\section{INTRODUCTION}

The global movement to replace fluorescent lamps with LED devices for saving energy is an important issue in recent lighting markets [1]-[7]. In particular, the LED drivers compatible with existing rapid-start ballasts have a major market in Japan, where urgent countermeasures to solve the electrical power shortage [8]-[10] are becoming crucial after the Tohoku earthquake. To meet the market demand, a passive type LED driver has been developed [11]-[15], which will be briefly introduced in this paper.

An immediate, economic, and practical solution to reduce lighting power is to remove one of the fluorescent lamps from a dual fluorescent lamps fixture. However, in a dual lamp type rapid-start ballast where two fluorescent lamps are serially connected, a fluorescent lamp will not light if one of them is simply pulled out.

A solution to this problem is a conventional dummy load that can be used as a substitute for the removed fluorescent [16], where the dummy load is made of a capacitors and a resistor. However, a dummy load has many problems: a large power loss in the rapid-start ballast, a reduced lifetime of the fluorescent lamp due to overcurrent, and a large total harmonic distortion (THD) which can cause malfunctions in power electronic devices [17]-[19]. Hence the conventional dummy loads used in rapid-start ballasts cannot meet THD regulations

Manuscript received Aug. 25, 2011; revised Aug. 7, 2012

Recommended for publication by Associate Editor Yong-Chae Jung.

${ }^{\dagger}$ Corresponding Author: ctrim@kaist.ac.kr

Tel: +82-42-350-3883, Fax: +82-42-350-5867, KAIST

*Department of Nuclear and Quantum Engineering, KAIST, Korea

${ }^{* *}$ Department of Electrical Engineering, KAIST, Korea

*** Optomind Inc., Korea and they undergo the danger of fire due to overheating.

In this paper, a new dummy load that overcomes these problems, where a few sets of LC series filters provide the same lamp current and diminish source side harmonic current, is proposed. The superiority of the proposed dummy load is verified by a comparison with a conventional dummy load.

\section{PREVIOUS WORKS ON PASSIVE LED DRIVERS}

In this section, the passive type LED drivers compatible with rapid-start ballasts, developed for the purpose of reducing power [11]-[14], are briefly introduced. The cause of fires in an LED driver with an SMPS is the large DC input capacitor of the SMPS, which can destroy the capacitor in a rapid-start ballast due to the excessive initial resonant voltage [11]-[14]. Furthermore, a SMPS usually suffers from harmonic distortions, EMI, a relatively short life time, and complexity caused by control integrated circuit [15].

Two types of LED drivers to solve these problems have been developed. The first type, shown in Fig. 1(a), is a $20 \mathrm{~W}$ passive LED driver compatible with rapid-start ballasts, which gives luminance similar to that of a traditional $40 \mathrm{~W}$ fluorescent lamp [11]-[13]. This type is made of a compensation circuit composed of passive elements. The compensation circuit was designed to meet requirements such as the output power, the input power factor, and the total harmonic distortion.

The compensation capacitor Cc makes the input power factor of a rapid-start ballast close to unity. The compensation inductors $L_{c 1}, L_{c 2}, L_{c 3}$, and $L_{c 4}$ are used to maintain the same resonant frequency as the original rapid-start ballast for conventional fluorescent lamps. To connect the LED lamp freely regardless of the polarity of the rapid-start ballast, four 


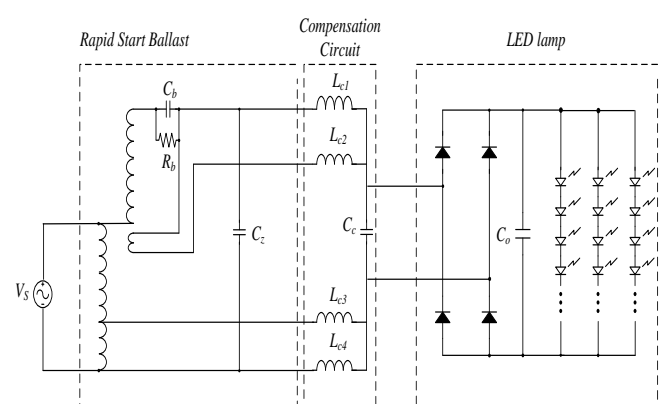

(a) 20W passive LED driver.

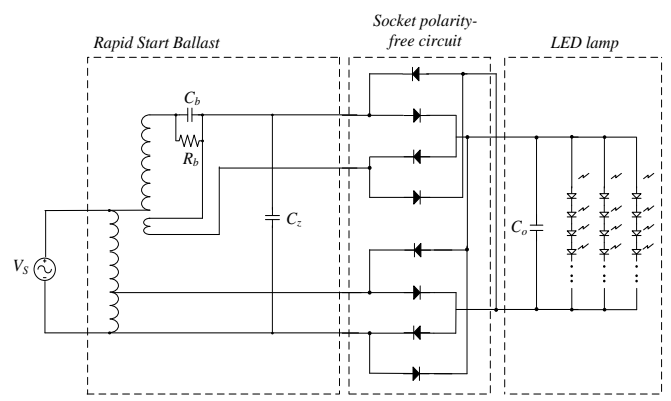

(b) 40W LED driver using a socket polarity free circuit.

Fig. 1. Two types of LED drivers proposed in [12]-[13].

inductors were used. This LED driver used a small DC capacitor to prevent the fires found in conventional rapid-start ballasts.

The second type is a $40 \mathrm{~W}$ LED driver using a socket polarity-free circuit, as shown in Fig. 1(b). It gives the same output power as a traditional $40 \mathrm{~W}$ fluorescent lamp (patent pending). The socket polarity-free circuit consists of two pairs of common anode and common cathode diode modules, allowing for the maximum output voltage at the either end of an LED array. This type of driver also used a small DC capacitor to avoid fires in the same manner as the $20 \mathrm{~W}$ passive LED driver.

These two LED drivers have advantages such as high robustness, low harmonic distortion, long lifetime, and safety when compared with conventional SMPS LED drivers. Thus the developed LED drivers are under tests for practical use and may reduce power consumption.

\section{THE PROPOSED DUMMY LOAD}

In an effort to reduce power consumption in lighting since the Fukushima nuclear accident in Japan, a dummy load to replace one fluorescent lamp in a dual lamp has drawn a great deal of attention.

When replacing the conventional two fluorescent lamps with a fluorescent lamp and a dummy load in a dual fluorescent lamp fixture, the following three requirements should be met.

The first requirement is to maintain the same operating

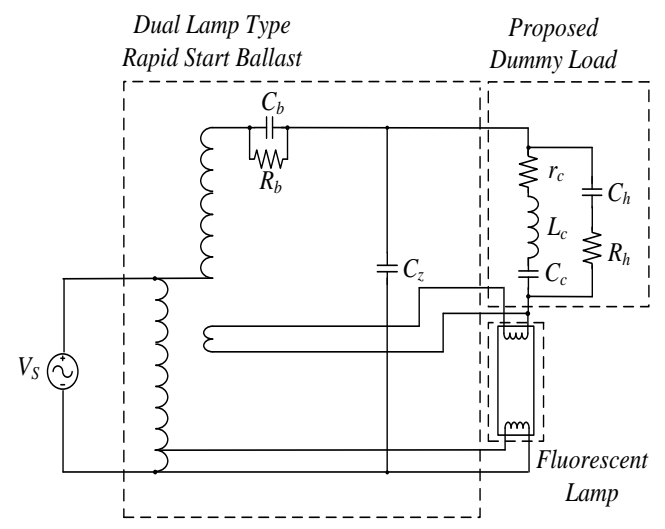

Fig. 2. The dual fluorescent lamp fixture with the proposed dummy load.

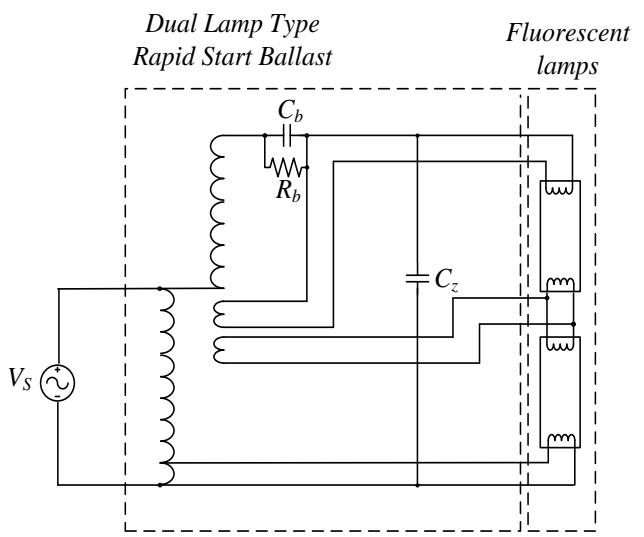

(a) The dual fluorescent lamp fixture with conventional two fluorescent lamps.

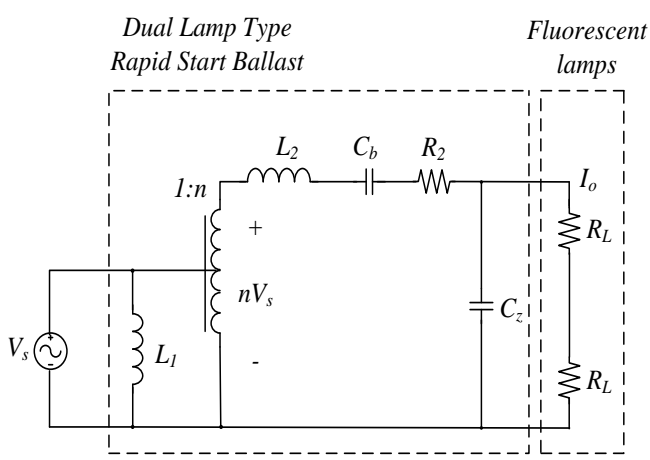

(b) The simple equivalent circuit of (a).

Fig. 3. The dual fluorescent lamp fixture and its simple equivalent circuit.

conditions, which are the output power, voltage, and current of the remaining fluorescent lamp. The second is to guarantee the input power factor which should be above 0.9. The last is to keep the THD of the source current under the THD regulation.

A dummy load which meets these design requirements is 


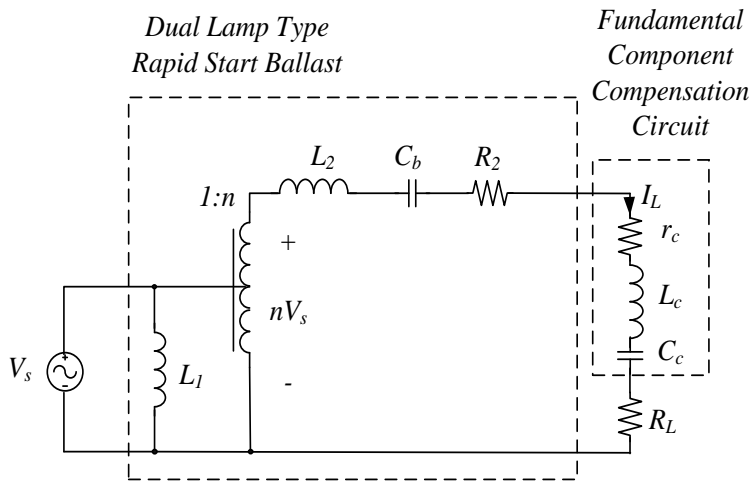

Fig. 4. The equivalent circuit of the dual fluorescent lamp fixture with the fundamental component compensation circuit.

proposed in this paper, as shown in Fig. 2. The design procedures for the proposed dummy load are explained in this section.

\section{A. Design of the Dummy Load}

To meet the design requirements, the proposed dummy load is designed to be composed of a fundamental component compensation circuit and a harmonic component filter circuit.

The dual fluorescent lamp fixture, which contains two lamps in series with a rapid-start ballast, is shown in Fig. 3(a). For the sake of simplicity, Fig. 3(a) is represented as a simple equivalent circuit, as shown in Fig. 3(b) [12], [13]. Here, $L_{1}$ is the equivalent inductance from the primary side including the magnetizing inductance of the transformer, and $L_{2}$ is the equivalent inductance from the secondary side including the leakage inductances of the transformer. $n$ is the turn ratio of the transformer. $R_{L}$ is the equivalent resistor for a fluorescent lamp. $R_{2}$ is the equivalent parasitic serial resistor inside the rapid-start ballast. The capacitor $C_{z}$ is relatively small at the fundamental frequency, and the resistor $R_{b}$ is large enough so that they can be negligible in the simple equivalent circuit. $r_{c}$ is the equivalent parasitic resistor of the inductor in the dummy load.

Basically, passive elements which have little power dissipation are used for the proposed dummy load, and the fundamental component compensation circuit consists of an inductor $L_{c}$ and a capacitor $C_{c}$.

Fig. 4 illustrates an equivalent circuit of the dual fluorescent lamp fixture where a fluorescent lamp is replaced with the fundamental component compensation circuit.

If the load current $I_{L}$ in Fig. 4 has same value as $I_{o}$ in Fig. 3 (b) at the fundamental frequency, the operating conditions of each fluorescent lamp in Fig. 3(b) and the remaining

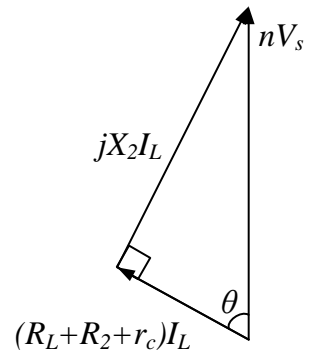

Fig. 5. The vector diagram of Fig. 4.

fluorescent lamp in Fig. 4 are equalized. The vector diagram of Fig. 4 is illustrated as shown in Fig. 5. The secondary side reactance of the rapid-start ballast in Fig. 4, $X_{2}$, is defined as follows:

$$
\begin{gathered}
X_{2}=\omega L_{t}-\frac{1}{\omega C_{t}} \\
L_{t}=L_{2}+L_{c} \\
C_{t}=\left(\frac{1}{C_{b}}+\frac{1}{C_{c}}\right)^{-1}
\end{gathered}
$$

Using the vector diagram of Fig. 5, the value of $X_{2}$ can be derived as follows:

$$
\begin{aligned}
\left(n V_{s}\right)^{2} & =I_{L}{ }^{2}\left(R_{L}+R_{2}+r_{c}\right)^{2}+I_{L}{ }^{2} X_{2}{ }^{2} \\
X_{2} & =\sqrt{\frac{n^{2} V_{s}^{2}}{I_{L}^{2}}-\left(R_{L}+R_{2}+r_{c}\right)^{2}}
\end{aligned}
$$

To find the values of $L_{c}$ and $C_{c}$, the values of $n, L_{1}$ and $L_{2}$ should be defined. The turn ratio $n$ and inductances $L_{1}$ and $L_{2}$ vary with the source voltage and load current due to the non-linearity of the rapid-start ballast [12], [13].

Fig. 6(a) and (b) represent the variations of $n, L_{1}$ and $L_{2}$ with a load current when the source voltage is $100 V_{r m s}$, which is the operating voltage of the rapid-start ballast.

The current of each fluorescent lamp is about $340 \mathrm{~mA}$ in Fig. 3(b). Therefore, the values of $n, L_{1}$, and $L_{2}$ are selected as 2.35, $0.65 \mathrm{H}$, and $0.99 \mathrm{H}$, respectively. Using (1)-(5) with above selected values of $n, L_{1}$, and $L_{2}$, several combinations of $L_{c}$ and $C_{c}$ can be obtained. 


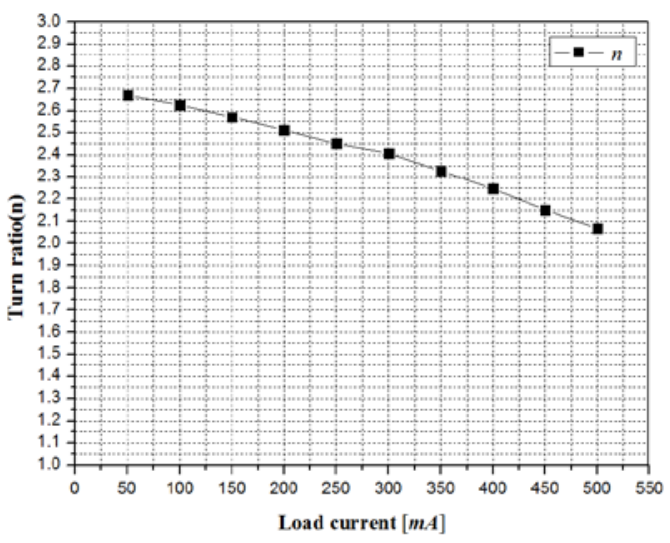

(a) The variation characteristics of $n$.

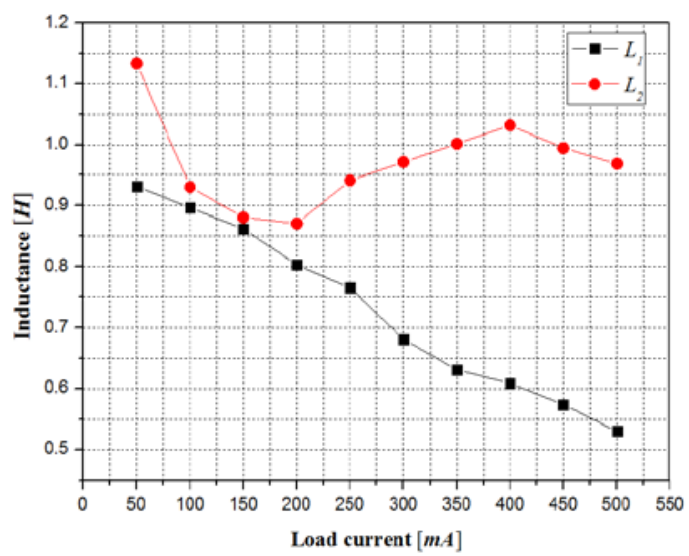

(b) The variation characteristics of L1 and L2.

Fig. 6. The characteristics of the dual lamp type rapid-start ballast.

The input power factor, which is the second design requirement, can be obtained over 0.95 for all combinations through the following equation:

$$
p \cdot f .=\frac{I_{L} \cos \theta}{\sqrt{\left(\frac{V_{s}}{n \omega L_{1}}-I_{L} \sin \theta\right)^{2}+\left(I_{L} \cos \theta\right)^{2}}}
$$

where $\cos \theta$ and $\sin \theta$ are defined as follows:

$$
\begin{gathered}
\cos \theta=\frac{I_{L}\left(R_{L}+R_{2}+r_{c}\right)}{n V_{s}} \\
\sin \theta=\frac{I_{L} X_{2}}{n V_{s}}
\end{gathered}
$$

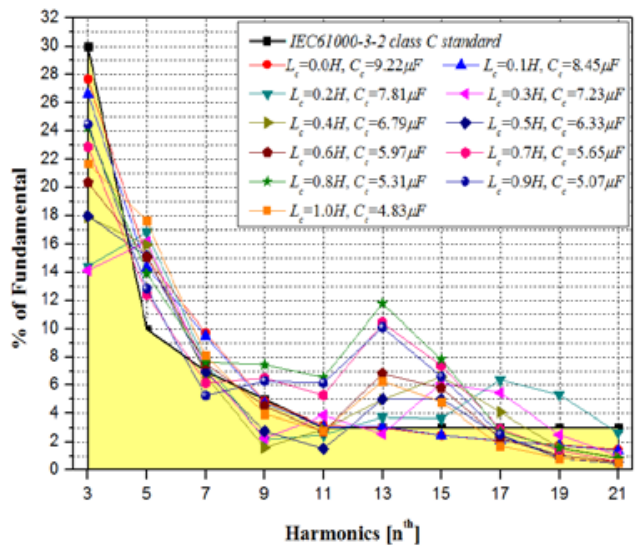

Fig. 7. The measured source side harmonic currents with combinations of $L_{c}$ and $C_{c}$.

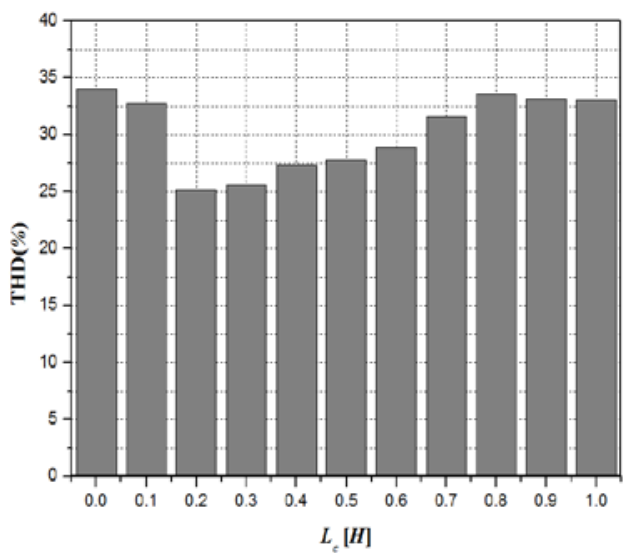

Fig. 8. The measured THD with combinations of $L_{c}$ and $C_{c}$.

From the view point of manufacturing, a small inductor size is desirable. As a result, the value of inductor $L_{c}$ is selected among $0.1 \sim 1.0 \mathrm{H}$ in the following design processes and experiments.

To find an optimal combination of $L_{c}$ and $C_{c}$, the third design requirement, which is to keep the THD of the source current under the THD regulation, is considered. However, it is not entirely possible to characterize the source side harmonic currents because of the non-linearity in the rapid-start ballast [12], [13]. Hence it is necessary to measure the THD characteristics by experiments for the above $L_{c}$ and $C_{c}$ combinations. The measured source side harmonic currents, shown as a percentage of the fundamental current, are given in Fig. 7. The measured THD for the above combinations of $L_{c}$ and $C_{c}$ is illustrated in Fig. 8.

In Fig. 7, all of the above combinations of $L_{c}$ and $C_{c}$ exceeds the THD regulation which is the IEC61000-3-2 class $\mathrm{C}$ standard. Therefore, it is verified that a harmonic component filter circuit is essential to satisfy the THD regulation. 
Prior to the harmonic component filter circuit design, the optimal values of $L_{c}$ and $C_{c}$ are determined to be $0.2 \mathrm{H}$ and $7.81 \mu \mathrm{F}$, respectively. This is done by considering the lowest THD among the above combinations of $L_{c}$ and $C_{c}$, as shown in Fig. 8.

To design the harmonic component filter circuit, capacitor $C_{z}$ in the rapid-start ballast, which was ignored at the fundamental frequency, should be considered. The harmonic component filter circuit consists of a capacitor $C_{h}$ and a resistor $R_{h}$. Fig. 9 shows the equivalent circuit which includes $C_{z}$ and the harmonic component filter circuit.

It is identified that the $5^{\text {th }}$ source side harmonic current exceeds the THD regulation more than the other harmonic currents, as shown in Fig 7. Hence it is essential to diminish the $5^{\text {th }}$ source side harmonic current by using the harmonic component filter circuit. A method to reduce the $5^{\text {th }}$ source side harmonic current is by increasing $\left|Z_{T}(j \omega)\right|$ at the $5^{\text {th }}$ harmonic, which is the amplitude of impedance $Z_{T}$, as shown in Fig. 9.

$\left|Z_{T}(j \omega)\right|$ is expressed as follows:

$$
\begin{gathered}
\left|Z_{T}(j \omega)\right|=\sqrt{\frac{\gamma^{2}+\delta^{2}}{\alpha^{2}+\beta^{2}}} \\
\alpha=\omega^{4} L_{c} C_{z}\left(R_{h}+R_{L}\right)-\omega^{2}\left\{R_{h}\left(1+\frac{C_{z}}{C_{c}}\right)+r_{c}\left(1+\frac{C_{z}}{C_{h}}\right)+R_{L} C_{z}\left(\frac{1}{C_{c}}+\frac{1}{C_{h}}\right)\right\} \\
\beta=-\omega^{3}\left[L_{c}\left(1+\frac{C_{z}}{C_{h}}\right)+C_{z}\left\{R_{h}\left(R_{L}+r_{c}\right)+R_{L} r_{c}\right\}\right]+\omega\left(\frac{C_{c}+C_{h}+C_{z}}{C_{c} C_{h}}\right) \\
\gamma=-\omega^{2}\left\{\frac{L_{c}}{C_{h}}+R_{h}\left(R_{L}+r_{c}\right)+R_{L} r_{c}\right\}+\frac{1}{C_{c} C_{h}} \\
\delta=-\omega^{3} L_{c}\left(R_{h}+R_{L}\right)+\omega\left(\frac{R_{h}+R_{c}}{C_{c}}+\frac{R_{c}+r_{c}}{C_{h}}\right)
\end{gathered}
$$

The value of $C_{h}$, which results in the highest $\left|Z_{T}(j \omega)\right|$ at the $5^{\text {th }}$ harmonic, is obtained as $2.6 \mu F$ by using (9), where $C_{z}=180 n F$.

Although the $5^{\text {th }}$ source side harmonic current was reduced by the selected $C_{h}$, the other source side harmonic currents still exceed the THD regulation.

Therefore, $R_{h}$, which can decrease the other source side harmonic currents, should be added to the harmonic component filter circuit. 56.2 $\Omega$ was selected for $R_{h}$ by experiments because the effect of $R_{h}$ on the source side harmonic currents is not entirely possible to analyze. A new $\left|Z_{T}(j \omega)\right|$ curve can be obtained, as shown in Fig. 10.

\section{B. Experimental Verification}

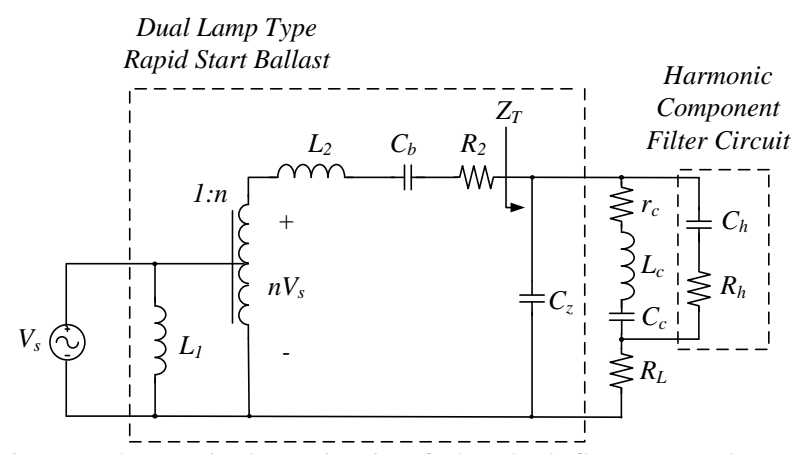

Fig. 9. The equivalent circuit of the dual fluorescent lamp fixture with the harmonic component filter circuit.

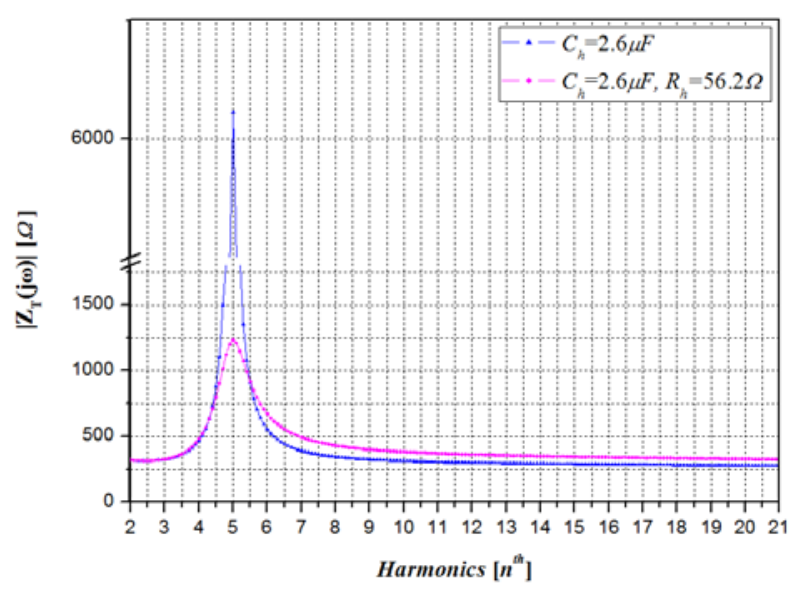

Fig. 10. The curves of $\left|Z_{T}(j \omega)\right|$.

By replacing the conventional two fluorescent lamps with a fluorescent lamp and the proposed dummy load in a dual fluorescent lamp fixture, the three design requirements can be satisfied through experiments.

First of all, the measured current, voltage, and power of the remaining fluorescent lamp were $325 \mathrm{~mA}, 110 \mathrm{~V}_{r m s}$, and $35.8 \mathrm{~W}$, respectively, at a $100 V_{\text {rms }}$ source voltage. These are almost identical to the operating conditions of a fluorescent lamp in the dual fluorescent lamp fixture, which are $343 m A, 104 V_{r m s}$, and $35.8 \mathrm{~W}$ at the same source voltage.

Secondly, the measured input power factor of the dual fluorescent lamp fixture was measured at 0.99 , when a fluorescent lamp had been replaced with the proposed dummy load.

Lastly, the THD of the source current was kept under the THD regulation, as shown in Fig. 11. 


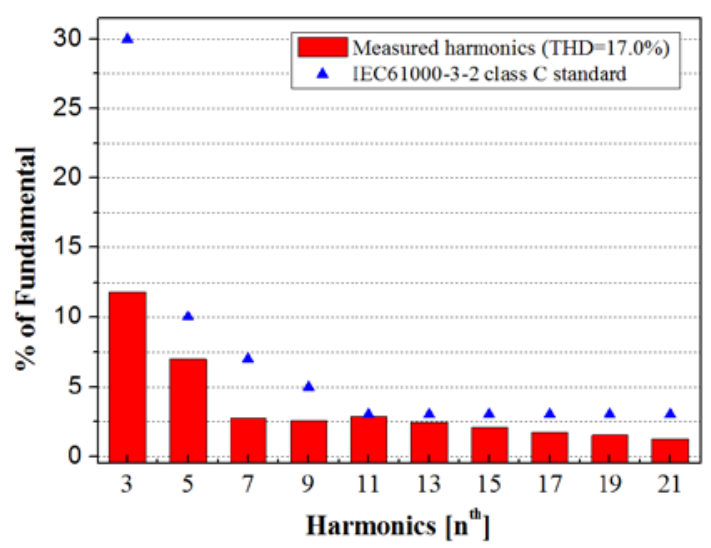

Fig. 11. The measured source side harmonic current of the dual fluorescent lamp fixture with the proposed dummy load.

TABLE I

EXPERIMENTAL CIRCUIT PARAMETERS

\begin{tabular}{lc}
\hline \hline Parameter & Value \\
\hline$V_{s}$ & $110 V_{\text {rms }}$ \\
$f_{s}$ & $60 \mathrm{~Hz}$ \\
$L_{c}$ & $0.2 \mathrm{H}$ \\
$C_{c}$ & $7.81 \mu \mathrm{F}$ \\
$C_{h}$ & $2.6 \mu \mathrm{F}$ \\
$R_{h}$ & $56.2 \Omega$ \\
\hline \hline
\end{tabular}

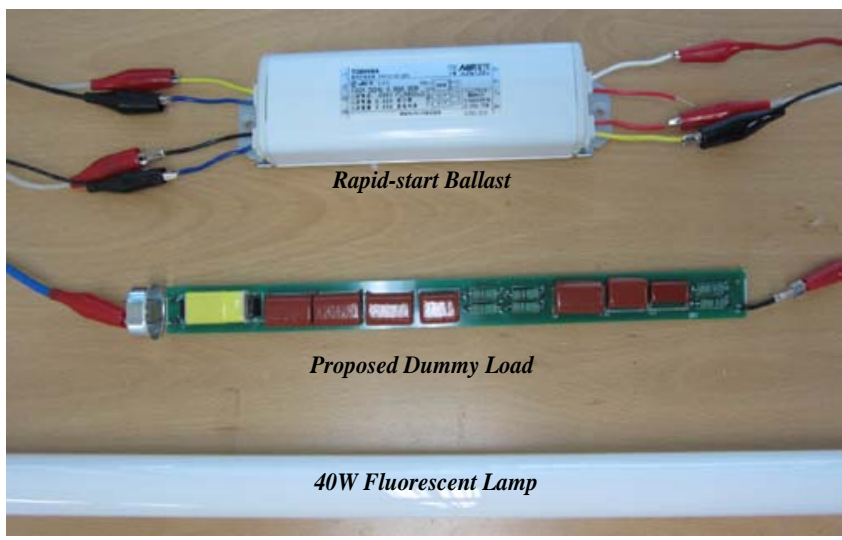

Fig. 12. A prototype of the proposed dummy load.

It is verified that the $5^{\text {th }}$ source side harmonic current was reduced by adding $C_{h}$ and that the other source side harmonic currents went down by the additional $R_{h}$. The experimental circuit parameters including the source voltage $V_{s}$, and the source frequency $f_{s}$ are summarized in Table I. The prototype of the proposed dummy load, as shown in Fig. 12, shows a compact size which can be installed in a typical fluorescent tube, which is $1.70 \times 47.5 \mathrm{~cm}^{2}$.
TABLE II

MeAsurement Result of Operating Conditions

\begin{tabular}{lccc}
\hline \hline Parameter & $\begin{array}{c}\text { Two fluorescent } \\
\text { lamps }\end{array}$ & $\begin{array}{c}\text { A fluorescent } \\
\text { lamp with a } \\
\text { conventional } \\
\text { dummy load }\end{array}$ & $\begin{array}{c}\text { A fluorescent } \\
\text { lamp with the } \\
\text { proposed } \\
\text { dummy load }\end{array}$ \\
\hline$I_{L}$ & $343 m A$ & $403 m A$ & $325 m A$ \\
$V_{L}$ & $104 V_{\text {rms }}$ & $109 V_{\text {rms }}$ & $110 V_{\text {rms }}$ \\
$P_{L}$ & $35.8 \mathrm{~W}$ & $44.0 \mathrm{~W}$ & $35.8 \mathrm{~W}$ \\
$P_{b}$ & $17.1 \mathrm{~W}$ & $18.9 \mathrm{~W}$ & $5.36 \mathrm{~W}$ \\
$P_{T}$ & $88.7 \mathrm{~W}$ & $62.9 \mathrm{~W}$ & $42.3 \mathrm{~W}$ \\
$p . f$. & 0.94 & 0.99 & 0.99 \\
\hline \hline
\end{tabular}

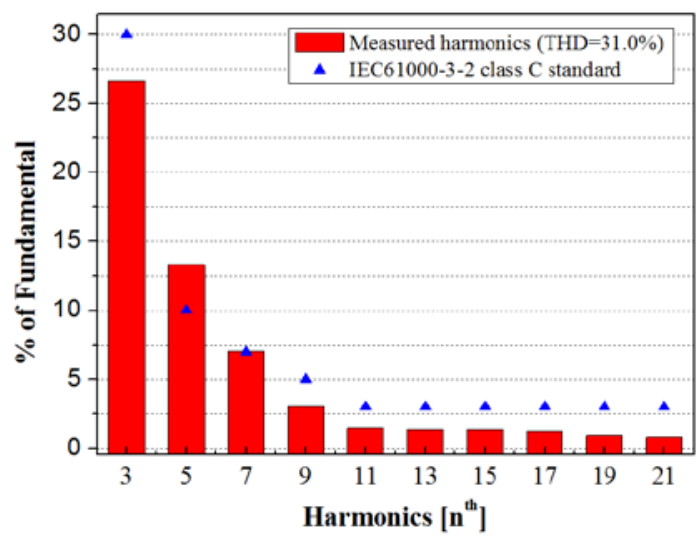

Fig. 13. The measured source side harmonic current of the dual fluorescent lamp fixture with the conventional dummy load.

\section{COMPARISON WITH A CONVENTIONAL DUMMY LOAD}

Several experiments for the comparative analysis of the proposed dummy load and a conventional dummy load were performed. The conventional dummy load is composed of two large electrolytic capacitors back-to-back connected with diodes.

The current $I_{L}$, voltage $V_{L}$, and power $P_{L}$ of the remaining fluorescent lamp, and the power of the rapid-start ballast $P_{b}$ together with the input power $P_{T}$ were measured by a WT1600 digital power meter, as summarized in Table II.

From the view point of energy savings, the input power $P_{T}$ should be minimized. $25.8 \mathrm{~W}$ can be saved by the conventional dummy load whereas $46.4 \mathrm{~W}$ can be conserved by the proposed dummy load.

It was observed that this simple conventional dummy load caused a much larger load current, which results in overload in the remaining fluorescent lamp. This over power consumption causes a life-shortening problem for the fluorescent lamp.

Moreover, the THD regulation was not met by the conventional dummy load, as shown in Fig. 13, since there 
is no harmonic filter circuit in it.

\section{CONCLUSIONS}

The proposed dummy load composed of a fundamental component compensation circuit and a harmonic component filter circuit showed very good performances when compared with a conventional dummy load.

It provides $20.6 \mathrm{~W}$ increase in power savings when compared to the conventional dummy load while meeting the rated output current, power factor, and THD regulations faithfully.

Therefore, it can be concluded that the proposed dummy load is a practical and urgently needed countermeasure for the electrical power shortage in Japan.

\section{REFERENCES}

[1] B. Hefferman and I. Frater, "LED replacement for fluorescent tube lighting,” Power Engineering Conference, Australasian Universities, Dec. 2007.

[2] T. Taguchi, "Present status of energy saving technologies and future prospect in white LED lighting," Transactions on Electrical and Electronic Engineering, Vol. 3, No. 1, pp. 21-26, Jan. 2008.

[3] O. Yoshihiko, LED Illuminating Handbook, The Japan Institute of Illuminating, Japan, 2006.

[4] EU Union, "Directive on the restriction of the use of certain hazardous substances in electrical and electronic equipment," Feb. 2003.

[5] G. Sauerlander and D. Hente, "Driver electronics for LEDs," in IEEE Industry Applications Conference, pp. 2621-2626, 2006.

[6] Housing Research Institute Korea National Housing Corporation, "A study on the lighting fixture in apartments," Sep. 1996.

[7] L. Lau, "Electronic ballast circuit for a fluorescent light," US patent no. 5444333, Aug. 1995.

[8] P. Fairley, "Japan faces post-Fukushima power struggle," IEEE, Spectrum, pp. 13-14, Aug. 2011.

[9] Y. Fukushima, Y. Kikuchi, Y. Kajikawa, M. Kubota, T. Nakagaki, M. Matsukata, Y. Kato, and M. Koyama, "Tackling power outages in Japan : the earthquake compels a swift transformation of the power supply," Journal of Chemical Engineering of Japan, Vol. 44, No. 6, pp. 365-369, 2011.

[10] F. Fesharaki and T. Hosoe, "The Fukushima crisis and the future of Japan's power industry,” Asia Pacific Bulletin, N. 106, Apr. 2011.

[11] C. T. Rim, B. Lee, H. Kim, and B. C. Kim, "Power factor compensation-type LED lighting apparatus," Korea Patent, appl. no. 1020100099802, patent pending.

[12] C. T. Rim, B. Lee, and H. Kim, "Passive LED driver compatible with rapid-start ballast,” Power Electronics and ECCE Asia, pp. 507-514, May 2011.

[13] B. Lee, H. J. Kim, and C. T. Rim, "Robust passive LED driver compatible with conventional rapid-start ballast," IEEE Trans. Power Electron., Vol. 26, No. 12, pp. 3694-3706, Dec. 2011.
[14] C. T. Rim, "Unified general phasor transformation for AC converters," IEEE Trans. Power Electron., Vol. 26, No. 9, pp. 2465-2475, Sep. 2011.

[15] W. Chen, “A comparative study on the circuit topologies for offline passive light-emitting diode (LED) drivers with long lifetime \& high efficiency," IEEE Energy Conversion Congress and Exposition, pp. 724-730, Sep. 2010.

[16] H. Shigemi, K. Shinobu, and H.Masaru, "Dummy tube and two-tube series sequentially starting fluorescent lamp," Japan Patent, appl. no. 2006-012745, paten.t pending.

[17] J. C. Balda, D. C. Griffith, A. McEachern, T. M. Barmes, D. P. Hartmann, D. J. Phileggi, A. E. Emannuel, W. F. Horton, W. E. Reid, R. J. Ferraro, and W. T. Jewell, "Effects of harmonics on equipment," IEEE Trans. Power Del., pp. 672-680, Apr. 1993.

[18] A. Shahani, B. Singh, and G. Bhuvaneshwari, “A high performance three-phase telecom supply incorporating a HF switched mode rectifier with a phase shifted PWM controller," Journal of Power Electronics, Vol. 10, No. 3, pp. 219-227, May 2010.

[19] G. Moschopoulos and P. Jain, "A study of AC-DC PWM full-bridge integrated converter topologies," Journal of Power Electronics, Vol. 1, No. 2, pp. 107-116, Oct. 2001.

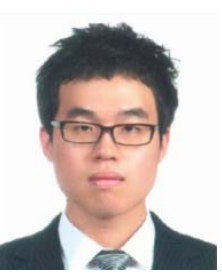

Bo-Hwan Choi received his B.S. from Sungkyunkwan University, Suwon, Korea, in 2011. He is currently pursuing an Integrated Master's Ph.D. in Nuclear and Quantum Engineering at KAIST (Korea Advanced Institute of Science and Technology), Daejeon, Korea. His research interests are in the field of power electronics related to nuclear power plants, and his current research interests include power conversion circuits and contactless power supplies.

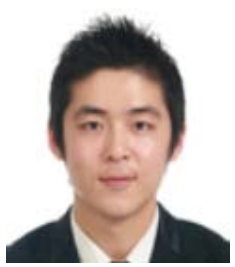

Hyun-Jae Kim received his B.S. from Sungkyunkwan University, Suwon, Korea, in 2010, and his M.S. from KAIST (Korea Advanced Institute of Science and Technology), Daejeon, Korea, in 2012, both in Electrical Engineering. His current research interests are in the field of power electronics related to LED drivers and contactless power supplies.

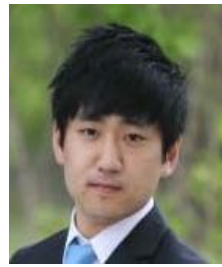

In-Yong Yeo received his B.S. from Hanyang University, Seoul, Korea, in 2011, and he is currently pursuing his M.S. in Nuclear Quantum Engineering at KAIST (Korea Advanced Institute of Science and Technology), Daejeon, Korea. His research interests are in the field of power electronics related to nuclear power plants, and his current research interests include power conversion circuits and contactless power supplies. 


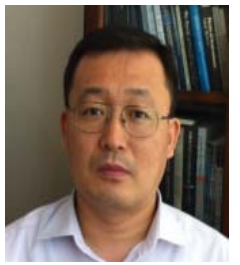

Bong-Cheol Kim was born on Jeju Island, Korea, in 1962. He received his B.S. in Electrical and Electronic Engineering from Ajou University, Suwon, Korea, in 1985 and his M.S. in Electrical and Electronic Engineering from KAIST (Korea Advanced Institute of Science and Technology), Daejeon, Korea, in 1987. From 1987 to 1990, he was with the Institute of Samsung Electronics, Kiheung, Korea. From 1991 to 2003, he organized and worked for PROWTech Inc. in the field of infrared and visible LEDs as a CTO of PROWTech Inc., Chungbuk, Korea. His research interests include opto-electronic components such as Laser Diode and LEDs, and also LED lighting solutions for general illumination. He is currently working on smart and robust LED driving technology development in the field of LED general lighting with KAIST as a president and CEO of Optomind Inc.

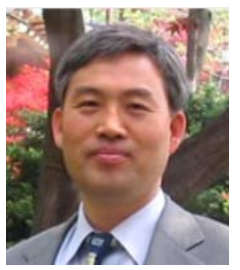

Chun-Taek Rim received his B.S. from KIT (Kumoh Institute of Technology), Gumi, Korea, in 1985, and his M.S. and Ph.D. from KAIST (Korea Advanced Institute of Science and Technology), Daejeon, Korea, in 1987 and 1990, respectively, all in Electrical Engineering. Since 2007, he has been an Associate Professor of Nuclear and Quantum Engineering at KAIST. From 1990 to 1995, he was a Military Officer. From 1995 to 2003, he was a Senior Researcher at the Agency for Defense Development. From 2003 to 2007, he was a Senior Director at the Presidential Office. He has authored or coauthored 62 papers, written 4 books, and holds 63 patents. He is currently developing an inductive power transfer systems for on-line electrical vehicles, and leading the Mobile Power Electronics Lab, named Tesla Lab, at KAIST. His research interests include future green transportation such as electrified vehicles, ships and airplanes, and wireless power systems for robots, home appliances and bio-medical applications. 